\title{
XPD Lys751Gln Polymorphisms and the Risk of Esophageal Cancer: An Updated Meta-Analysis
}

\author{
Xu-Feng Guo, Jun Wang, Xiao-Fei Lei, Yan-Ping Zeng and Wei-Guo Dong
}

\begin{abstract}
Objective Published data regarding the association between xeroderma pigmentosum group D XPD Lys751 Gln polymorphisms and esophageal cancer (EC) cancer remain controversial. The present meta-analysis aimed to obtain a more precise estimation of the relationship between XPD Lys751Gln polymorphisms and the risk of EC.

Methods All eligible case-control studies of Lys751Gln polymorphisms and susceptibility to EC were selected from PubMed, Web of Science and CNKI up to October 2013. The data were extracted, and pooled odds ratios (ORs) with $95 \%$ confidence intervals (CIs) were calculated.

Results A total of 21 case-control studies from 19 reports were assessed in this meta-analysis, including 6,581 cases and 8,251 controls. There was a significant association between the XPD Lys751Gln polymorphism and the risk of esophageal cancer in the overall population (Dominant model: OR=1.30, 95\%CI: 1.071.57, p<0.05; Lys/Gln vs. Gln/Gln: OR=1.20, 95\%CI: 1.05-137, p<0.05; Gln/Gln vs. Lys/Lys: OR=1.76, 95\% CI: $1.08-2.85, \mathrm{p}=0.02$; Recessive model: $\mathrm{OR}=1.48$, 95\%CI: 1.06-2.07, $\mathrm{p}=0.02$ ). Similar results were found when stratified according to the cancer type, ethnicity and control source. However, no associations were found among smokers or drinkers.
\end{abstract}

Conclusion The results of this meta-analysis suggest that XPD Lys751Gln polymorphisms contribute to susceptibility to EC.

Key words: XPD polymorphisms, esophageal cancer, ESCC, EADC, meta-analysis

(Intern Med 54: 251-259, 2015)

(DOI: 10.2169/internalmedicine.54.3256)

\section{Introduction}

Esophageal cancer (EC) is the sixth most common cause of cancer-related death worldwide (1), remaining one of the most deadly malignancies in China. EC is divided into two types according to biopsy findings: esophageal squamous cell carcinoma (ESCC) and esophageal adenocarcinoma (EADC). The five-year survival rate of ESCC is less than $10 \%$ in China and less than $20 \%$ in the USA (2). EADC is the most prevalent histologic form in North America and Europe, whereas ESCC is the most common histologic form found in China. Risk factors for EC include smoking, alcohol consumption, Barrett' esophagus and esophageal reflux disease (3-8).

Gene mutations are the most frequent cause of DNA dam- age. There are four DNA repair pathways, with the nucleotide excision repair (NER) pathway being the most versatile for lesion recognition and DNA repair (9). The xeroderma pigmentosum complementation group D (XPD) and xeroderma pigmentosum complementation group $\mathrm{C}$ (XPC) repair bulky DNA adducts. Experimental reports have suggested that XPD Lys751Gln (Lys $\rightarrow$ Gln) polymorphisms may increase susceptibility to esophageal cancer, lung cancer, bladder cancer and other digestive system cancers (10-14), and many molecular epidemiological studies have investigated the relationship between XPD Lys751Gln polymorphisms and the predisposition to esophageal cancer. However, the results of these reports remain inconclusive and inconsistent. Therefore, this meta-analysis aimed to evaluate the association between XPD Lys751Gln polymorphisms and susceptibility to esophageal cancer. 


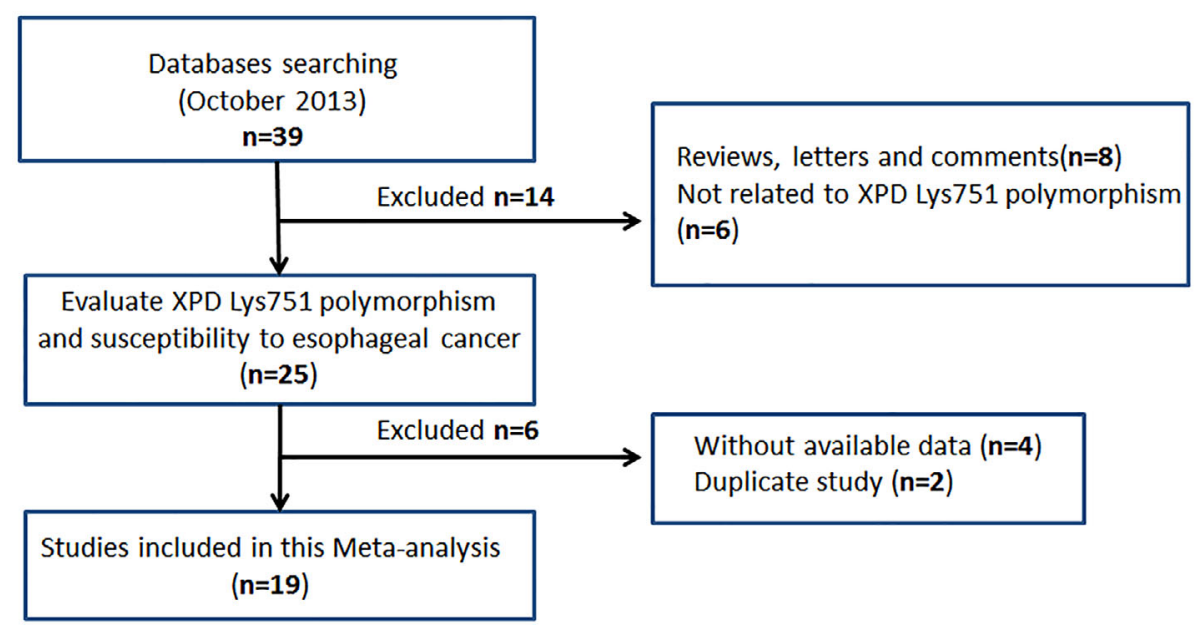

Figure 1. The flow chart of inclusion and exclusion

\section{Materials and Methods}

\section{Search strategy}

A comprehensive research was performed using PubMed, Web of Science, Embase and CNKI (up to October 2013), using the following key words: 'XPD polymorphisms or XPD Lys751Gln polymorphisms', 'genetic polymorphism or polymorphisms or variant', 'esophageal cancer', 'ERCC2' and 'DNA repair gene'. The search was limited to humans, without language restrictions. All eligible studies were examined carefully, and if more than one cancer type group was reported in a given report, then each type was extracted separately.

\section{Inclusion and exclusion criteria}

The included studies conformed to the following criteria: (1) an assessment of the association between XPD Lys751 Gln polymorphisms and esophageal cancer, (2) a casecontrol study design, (3) the inclusion of the detailed genotype frequencies of the cases and controls or data that could be calculated from the article text, (4) human subjects and (5) the inclusion of the sample size, odds ratio (OR) and 95\% confidence interval (CI). The major exclusion criteria were: (1) a case-only study design, (2) a lack of data regarding the XPD Lys751Gln genotype, (3) the inclusion of duplicate data, (4) case reports or review articles.

\section{Data extraction}

Information was carefully extracted from all eligible studies by two independent investigators (Guo X.F. and Wang J.). If the two investigators reported different results, a discussion was conducted in order to reach an agreement. Finally, an expert (Dong W.G.) was invited to verify the information. The included studies contained the following information: the first author's name, year of publication, country of origin, ethnicity, cancer type, genotyping methods and number of cases and controls. Ethnicities were categorized as Asian, European or mixed. The cancer type was categorized as ESCC or EADC.

\section{Statistical analysis}

The Cochrane Collaboration RevMan 5.1 software program was used in this meta-analysis. The $\chi^{2}$-test-based $\mathrm{Q}$ statistic test was performed to assess the degree of study heterogeneity (15). The effect of heterogeneity was quantified according to the $I^{2}$ value. A significant $\mathrm{Q}$ test $(\mathrm{p}<0.05)$ or $I^{2}>50 \%$ indicated heterogeneity across studies, in which case, the random effects model was used (16). Otherwise, the fixed effects model was applied (17). A professional web-based program (http://ihg2.helmholtz-muen- chen. de/ egibin/hw/hwal.pl) was used to assess the Hardy-Weinberg equilibrium of the controls. The dominant model (Lys/Gln+ $\mathrm{Gln} / \mathrm{Gln}$ vs. Lys/Lys), recessive model (Gln/Gln vs. Lys/ Gln+Lys/Lys) and co-dominant model (Lys/Gln vs. Lys/Lys and $\mathrm{Gln} / \mathrm{Gln}$ vs. Lys/Lys) were employed in this analysis. The level of publication bias was assessed according to Egger's and Begg's tests with the STATA Software 12.0 package. Funnel plots were also used to evaluate the degree of publication bias.

\section{Results}

\section{Study characteristics and results}

After being examined carefully according to the inclusion criteria, 20 studies were excluded and a total of 19 studies with 6,581 cases and 8,251 controls were included in the meta-analysis. A flow chart of the selection process is presented in Fig. 1. Two cancer types were included in the studies by Pan and Ye; therefore, there were 21 case-control studies in this meta-analysis $(23,28)$. As shown in Table 1 , there were 14 case-control studies, including 3,457 cancer cases and 4,855 controls, of the XPD Lys751Gln polymorphism and ESCC risk and seven studies, including 1,726 cases and 3,396 controls, of the XPD Lys751Gln polymorphism and EADC risk. A total of 12 studies focused on 
Table 1. Main Characteristics of All Studies Included in the Meta-analysis

\begin{tabular}{|c|c|c|c|c|c|c|c|c|c|}
\hline \multirow[t]{2}{*}{ References } & \multirow[t]{2}{*}{ Country } & \multirow[t]{2}{*}{ Ethnicity } & \multirow{2}{*}{$\begin{array}{l}\text { Control } \\
\text { Source }\end{array}$} & \multirow{2}{*}{$\begin{array}{l}\text { Cancer } \\
\text { Type }\end{array}$} & \multirow{2}{*}{$\begin{array}{l}\text { Genotyping } \\
\text { Method }\end{array}$} & \multicolumn{2}{|c|}{$\begin{array}{l}\text { Genotype } \\
\text { (case/control) }\end{array}$} & listribution & \multirow{2}{*}{$\begin{array}{l}\text { PHW } \\
\text { (p) }\end{array}$} \\
\hline & & & & & & Lys/Lys & Lys/Gln & $\mathrm{Gln} / \mathrm{Gln}$ & \\
\hline 18 & China & Chinese & HB & ESCC & PCR-RFLP & $150 / 274$ & $55 / 79$ & $8 / 5$ & 0.796 \\
\hline 19 & China & Chinese & PB & ESCC & PCR-RFLP & $264 / 289$ & $115 / 100$ & $26 / 16$ & 0.056 \\
\hline 20 & China & Chinese & $\mathrm{HB}$ & ESCC & PCR-RFLP & $283 / 321$ & $105 / 73$ & $12 / 6$ & 0.434 \\
\hline 21 & China & Chinese & $\mathrm{PB}$ & ESCC & PCR-Taq & $136 / 142$ & $86 / 79$ & $131 / 14$ & 0.499 \\
\hline 22 & China & Chinese & $\mathrm{HB}$ & ESCC & PCR-RFLP & $167 / 148$ & $31 / 51$ & $2 / 1$ & 0.122 \\
\hline 23 & America & European & HB & ESCC & PCR-Taq & $17 / 187$ & $18 / 216$ & $3 / 53$ & 0.431 \\
\hline 24 & China & Chinese & PB & ESCC & PCR-RFLP & $237 / 311$ & $79 / 76$ & $5 / 5$ & 0.884 \\
\hline 25 & China & Chinese & PB & ESCC & PCR-RFLP & $274 / 522$ & $51 / 86$ & $2 / 4$ & 0.824 \\
\hline 26 & India & Indian & PB & ESCC & PCR-RFLP & $52 / 63$ & $61 / 77$ & $7 / 20$ & 0.636 \\
\hline 27 & China & Chinese & $\mathrm{PB}$ & --- --- & PCR-RFLP & $91 / 95$ & $14 / 11$ & $1 / 0$ & 0.573 \\
\hline 28 & Sweden & European & $\mathrm{PB}$ & ESCC & PCR-RFLP & $23 / 198$ & $44 / 203$ & $14 / 71$ & 0.114 \\
\hline 29 & China & Chinese & HB & ESCC & PCR-RFLP & $108 / 133$ & $16 / 17$ & $11 / 2$ & 0.108 \\
\hline 30 & China & Chinese & HB & ESCC & PCR-RFLP & $278 / 331$ & $44 / 49$ & $3 / 3$ & 0.432 \\
\hline 31 & China & Chinese & $\mathrm{HB}$ & ESCC & PCR-RFLP & $367 / 451$ & $63 / 70$ & $3 / 3$ & 0.875 \\
\hline 23 & America & European & $\mathrm{HB}$ & EADC & PCR-Taq & $137 / 187$ & $153 / 216$ & $56 / 53$ & 0.431 \\
\hline 32 & Northern Ireland & European & $\mathrm{PB}$ & EADC & PCR-Taq & $80 / 91$ & $94 / 121$ & $34 / 35$ & 0.606 \\
\hline 33 & Canada & Mixed & HB & EADC & PCR-Taq & $104 / 193$ & $159 / 208$ & $49 / 52$ & 0.720 \\
\hline 34 & Australia & Mixed & $\mathrm{PB}$ & EADC & iPLEXTM & $108 / 575$ & $124 / 588$ & $311 / 174$ & 0.221 \\
\hline 35 & America & European & HB & EADC & PCR-RFLP & $61 / 143$ & $98 / 161$ & $23 / 32$ & 0.165 \\
\hline 28 & Sweden & European & $\mathrm{PB}$ & EADC & PCR-RFLP & $27 / 198$ & $51 / 203$ & $18 / 71$ & 0.114 \\
\hline 36 & Canada & Mixed & $\mathrm{HB}$ & EADC & PCR-RFLP & $31 / 34$ & $21 / 46$ & $4 / 15$ & 0.932 \\
\hline
\end{tabular}

PCR-RFLP: polymerase chain reaction-restriction fragment length polymorphism, PCR-Taq: polymerase chain reaction-thermus aquaticus, PB: population-based controls, HB: hospital-based controls, HDW: Hardy-Weinberg equilibrium, ESCC: esophageal squamous cell carcinoma, EADC: esophageal adenocarcinoma, p: value for HDW

Table 2. Results of Meta-Analysis for XPD Lys751Gln Polymorphism and Esophageal Cancer Risk

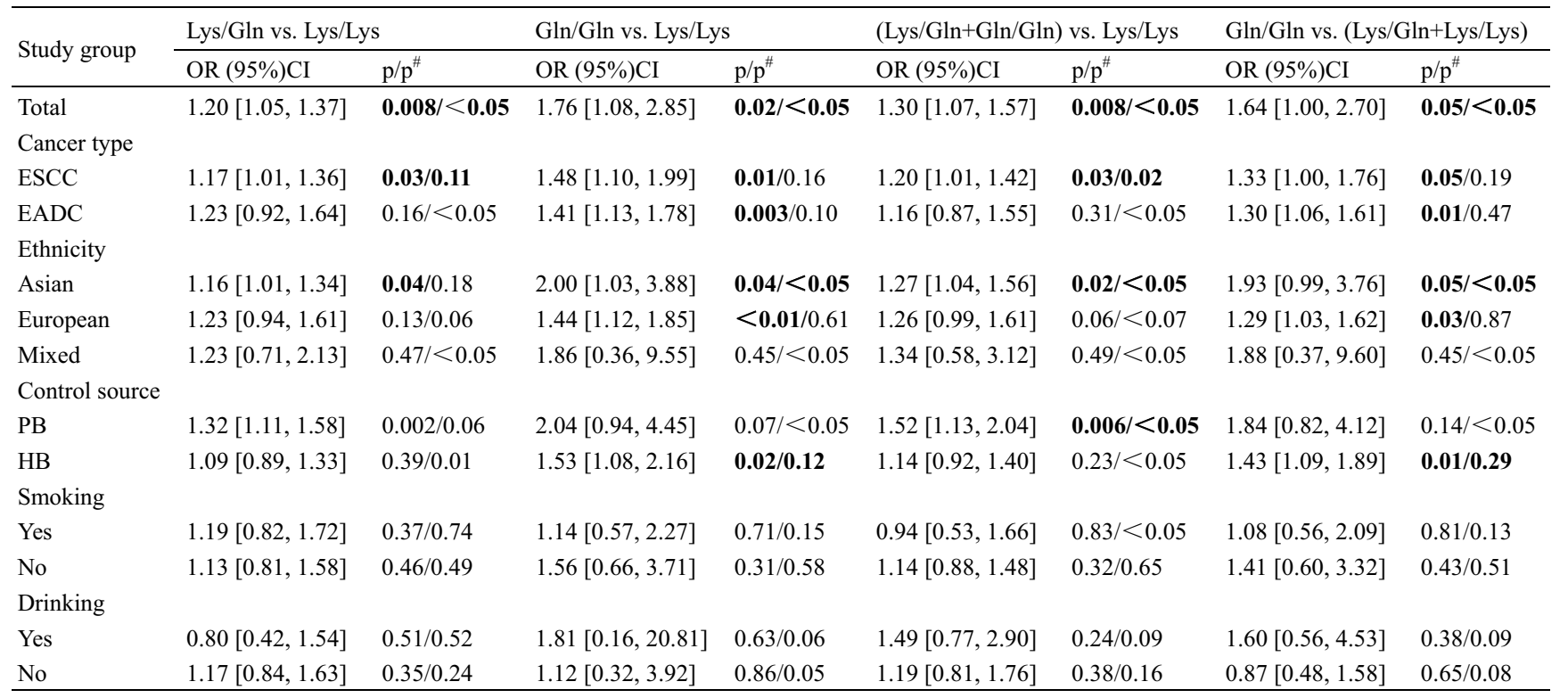

$\mathrm{p}$ : value for OR , p\#:value for heterogeneity, OR: odds ratio, CI: confidence interval, p\#<0.05: random-effect model was used: otherwise fixed-effect model was used.

Asian populations, six studies focused on European populations and three studies focused on mixed populations.

\section{Overall analysis}

The overall analysis showed significant between-study heterogeneity $\left(\mathrm{p}<0.05, I^{2}>50 \%\right)$; hence, the random effects model was used for the four models of each genotype. Con- sequently, there was a significant association between the XPD Lys751Gln polymorphism and the esophageal cancer risk in the overall population (Dominant model: $\mathrm{OR}=1.30$, 95\%CI: 1.07-1.57, p<0.05; Lys/Gln vs. Gln/Gln: $\mathrm{OR}=1.20$, 95\%CI: 1.05-137, p<0.05; Gln/Gln vs. Lys/Lys: OR=1.76, 95\%CI: $1.08-2.85, \mathrm{p}=0.02$; Recessive model: $\mathrm{OR}=1.48,95 \%$ CI: 1.06-2.07, $\mathrm{p}=0.02$ ) (Table 2, Fig. 2-5). In addition, the 


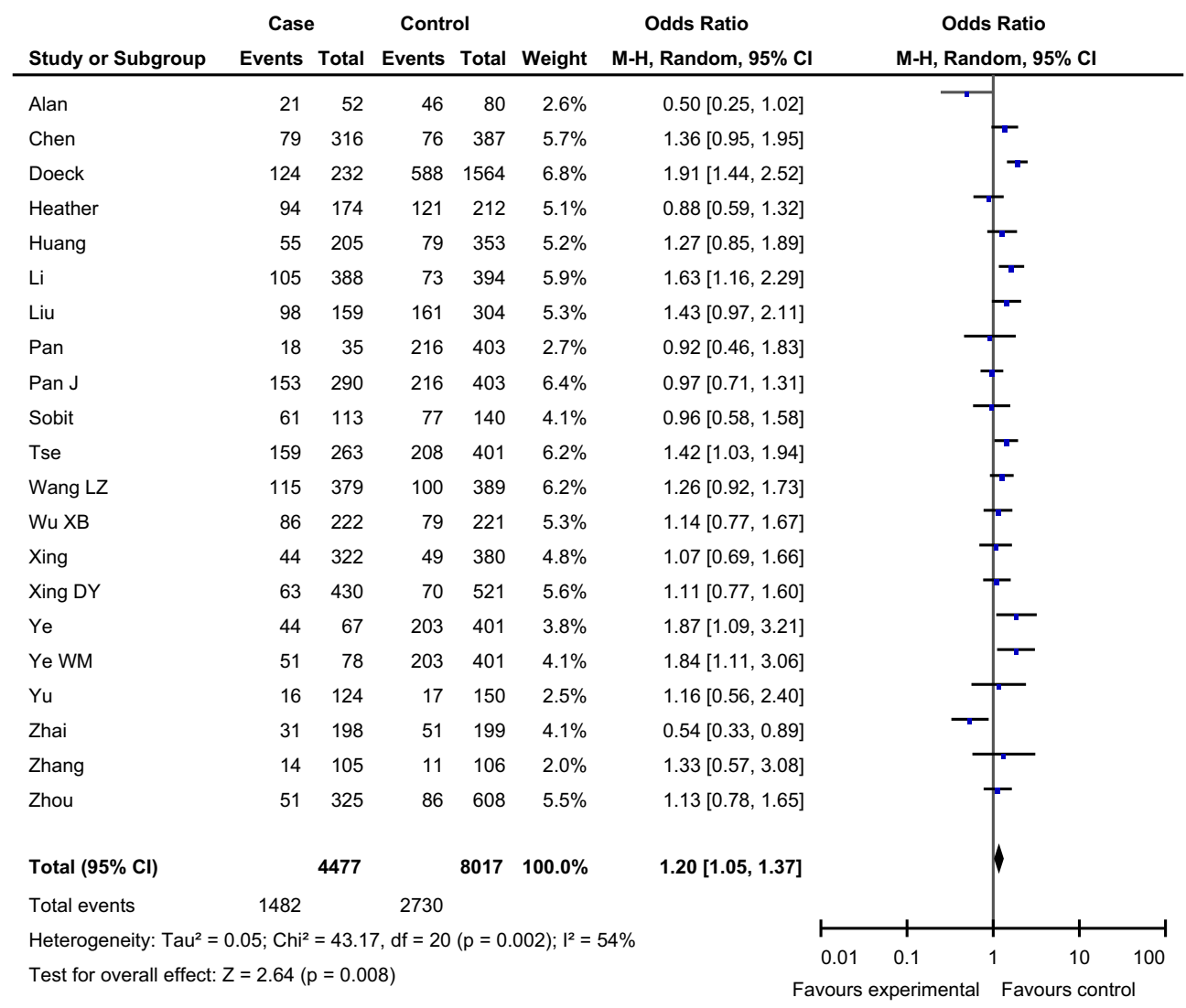

Figure 2. Overall analysis of XPD Lys751Gln polymorphism and esophageal cancer risk (Lys/GIn vs. Lys/Lys). The diamond represents the meta-analyzed effect measure.

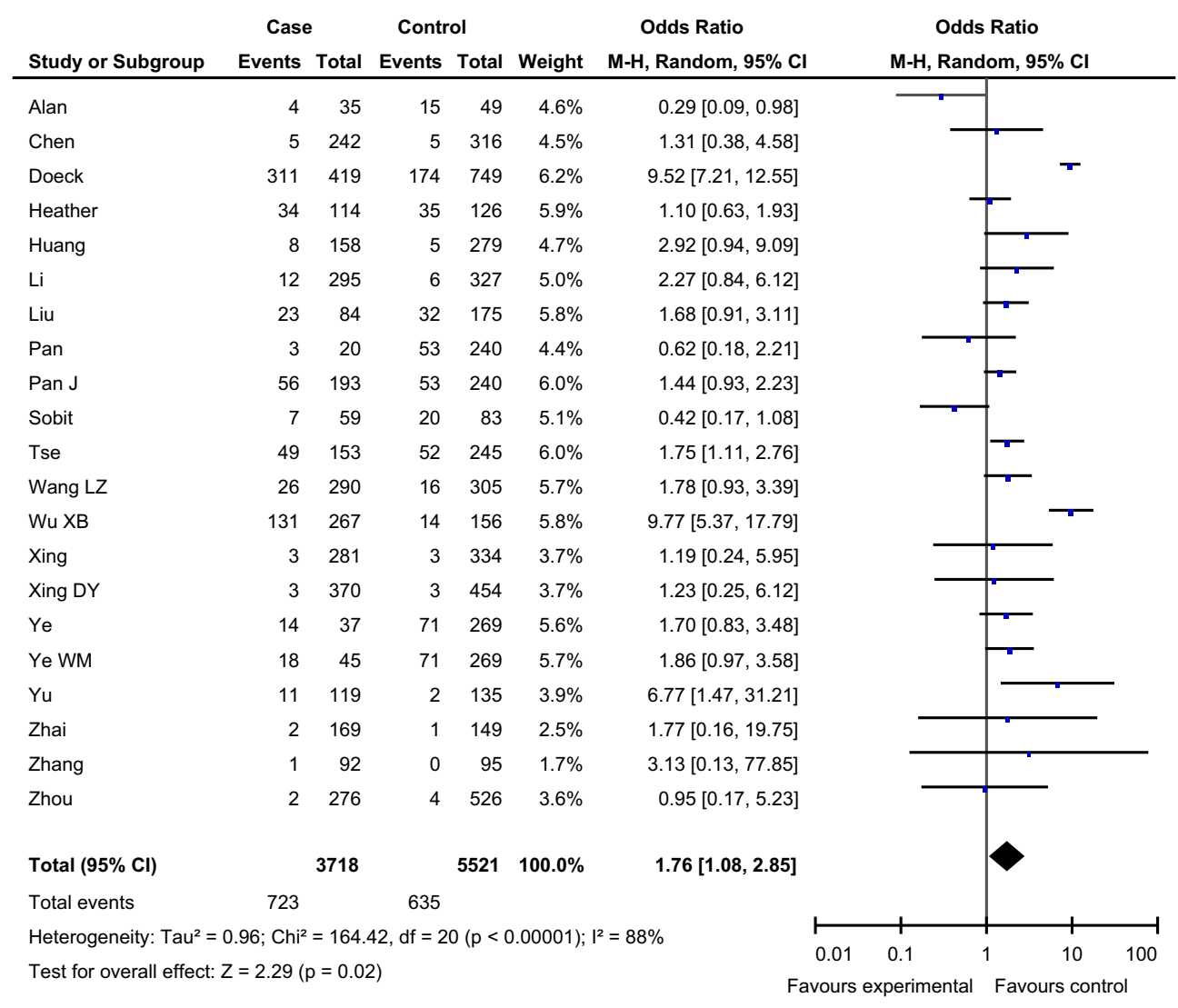

Figure 3. Overall analysis of XPD Lys751Gln polymorphism and esophageal cancer risk (GIn/GIn vs. Lys/Lys) 


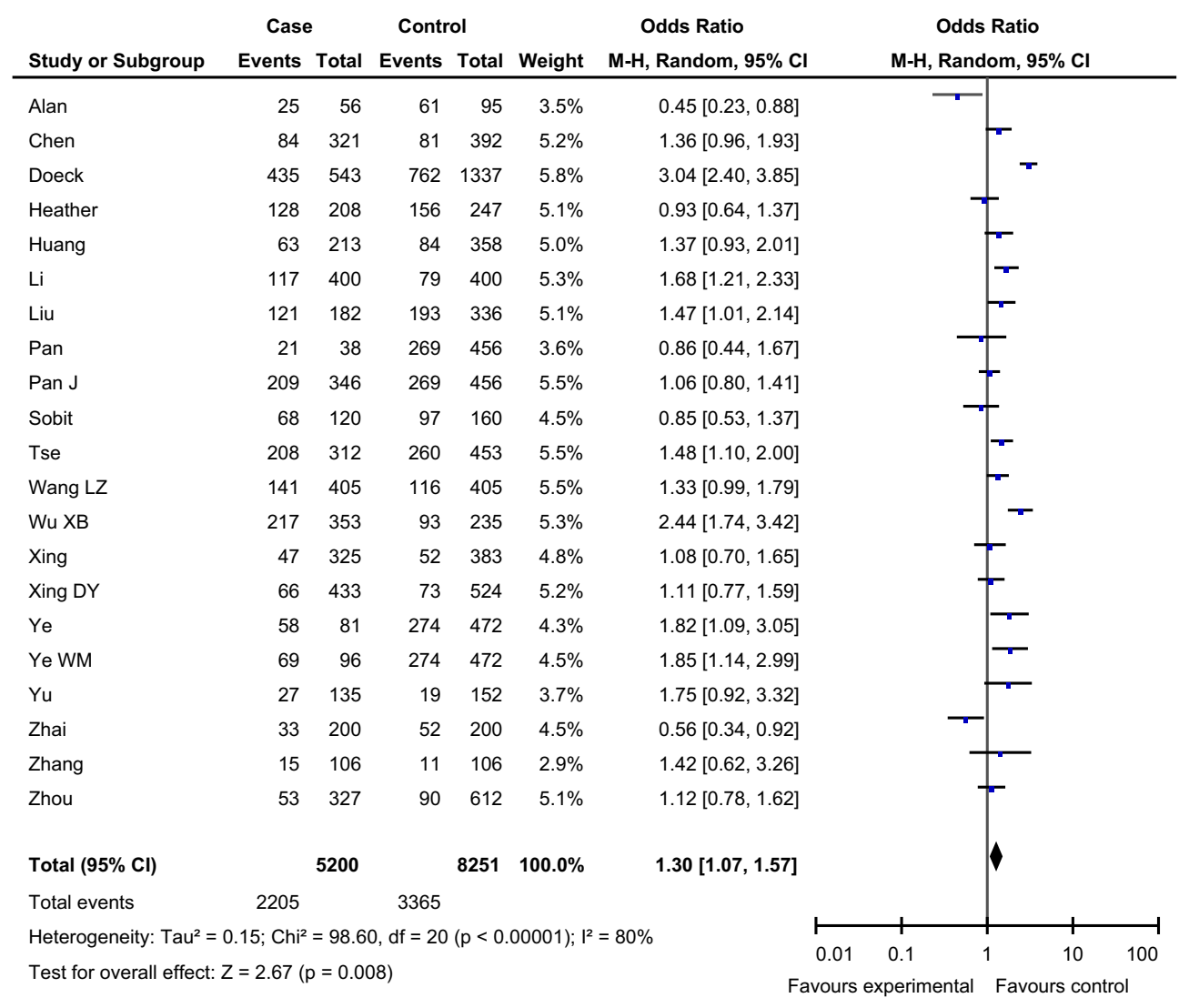

Figure 4. Overall analysis of XPD Lys751Gln polymorphism and esophageal cancer risk. [dominant model: (Lys/Gln+Gln/Gln) vs. Lys/Lys]

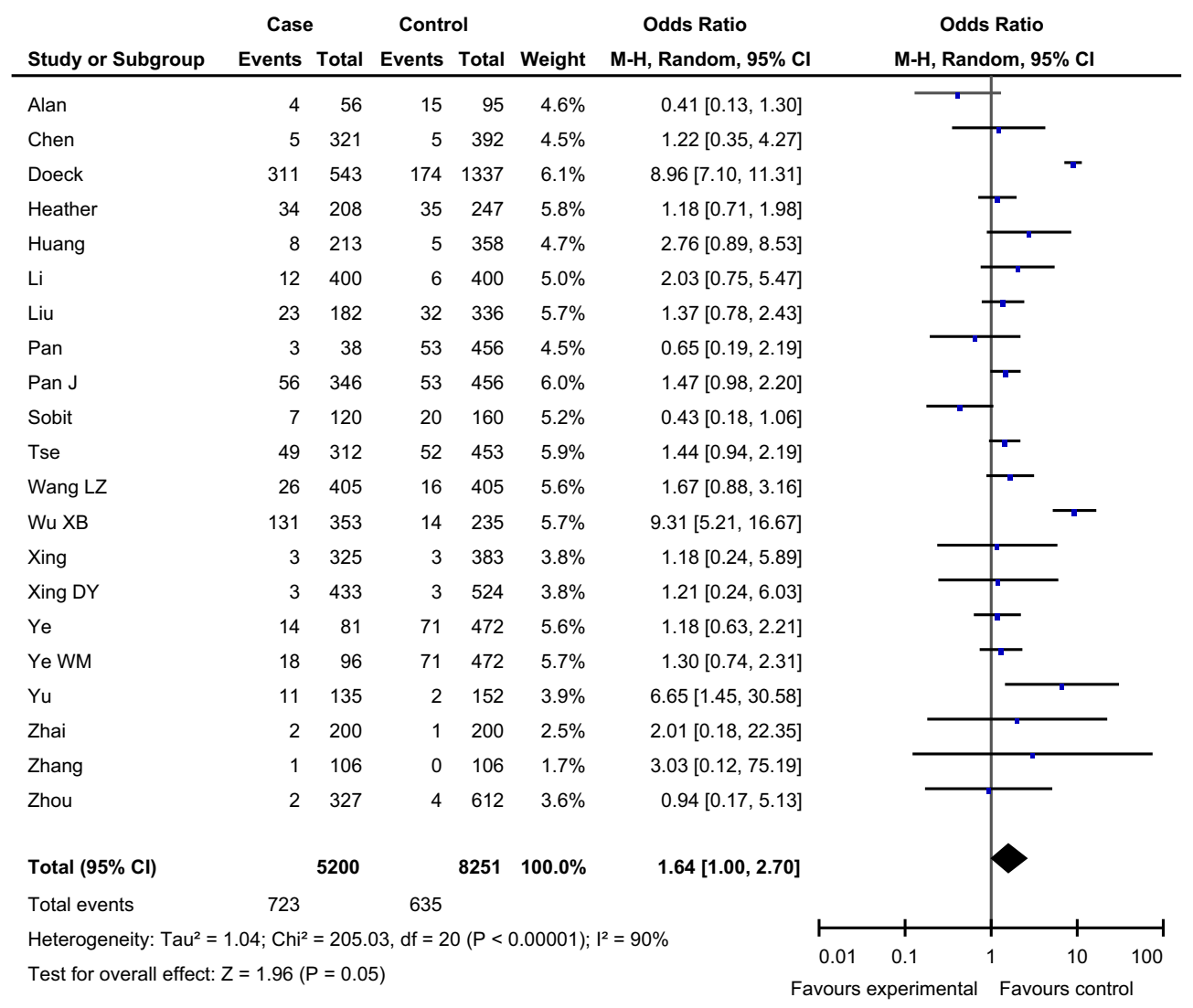

Figure 5. Overall analysis of XPD Lys751GIn polymorphism and esophageal cancer risk. [recessive model: Gln/Gln vs. (Lys/GIn+Lys/Lys)] 


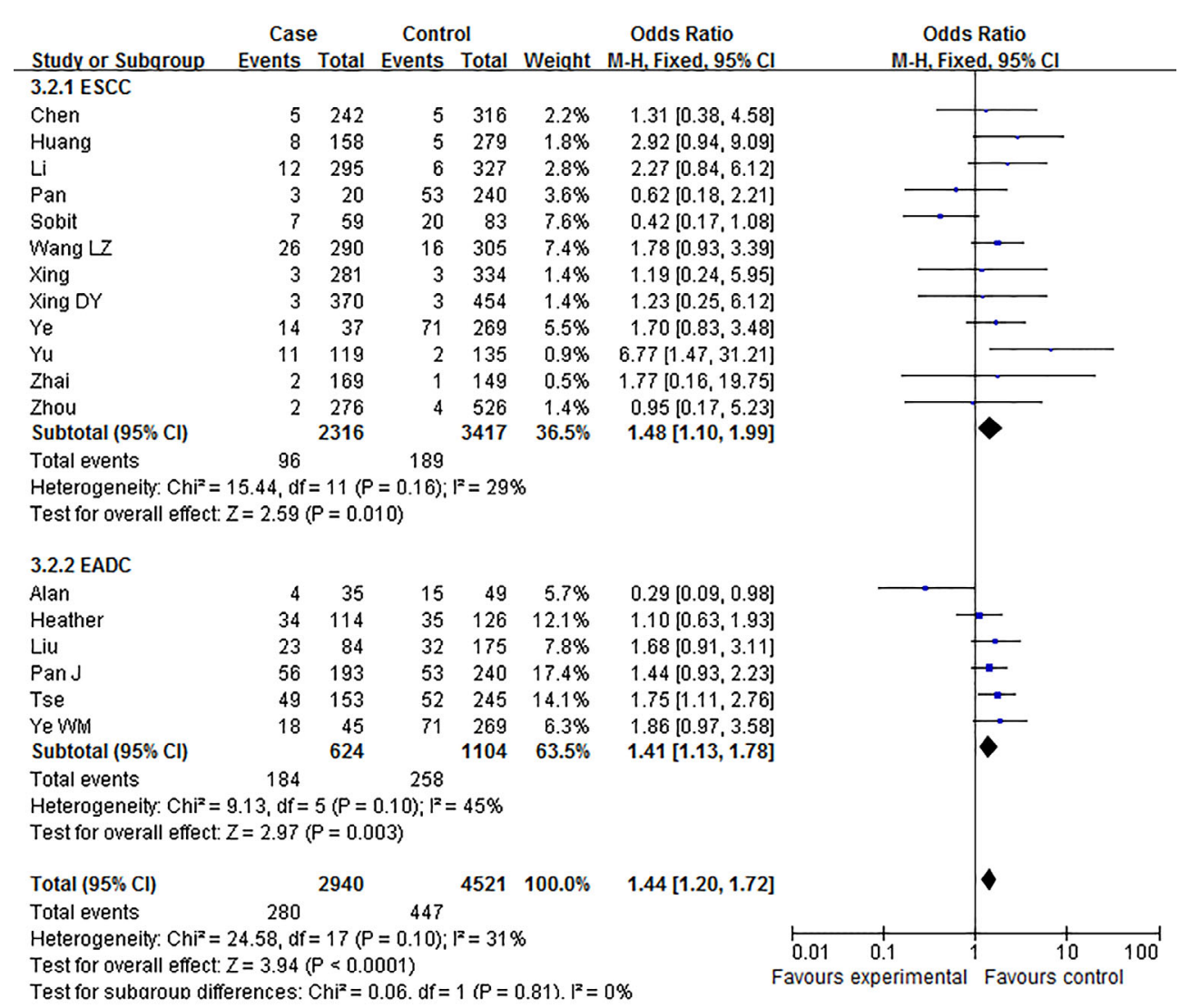

Figure 6. Subgroup analysis of XPD Lys751 polymorphism and esophageal cancer risk by cancer type. (GIn/GIn vs. Lys/Lys)

results showed that the XPD Lys751Gln polymorphism moderately increased the risk of EC.

\section{Subgroup analysis}

In the subgroup analysis according to cancer type, we observed a significant association between the Lys751Gln polymorphism and the risk of ESCC in three models (Dominant model: $\mathrm{OR}=1.27,95 \% \mathrm{CI}$ : $1.04-1.55, \mathrm{p}=0.02$; Lys $/ \mathrm{Gln}$ vs. Gln/Gln: $\mathrm{OR}=1.17$, 95\%CI: $1.01-1.36, \mathrm{p}=0.03 ; \mathrm{Gln} / \mathrm{Gln}$ vs. Lys/Lys: $\mathrm{OR}=1.79$, 95\%CI: 0.99-3.21, $\mathrm{p}=0.05$; Fig. 6). However, no significant associations were found in the four models for the risk of EADC (Dominant model: $\mathrm{OR}=1.32$, 95\%CI: $0.87-2.00, \mathrm{p}=0.19$; Lys/Gln vs. Gln/Gln: $\mathrm{OR}=1.23$, 95\%CI: 0.92-1.64, $\mathrm{p}=0.16$; Gln/Gln vs. Lys/Lys: OR=1.41, 95\%CI: $1.13-1.78, \mathrm{p}=0.23$; Recessive model: $\mathrm{OR}=1.56,95 \%$ CI: $0.67-3.65, p=0.31$; Fig. 6). When stratified according to ethnicity, the results showed a statistically elevated risk for Asians and Europeans, but not mixed populations (Asian: Dominant model: OR=1.27, 95\%CI: 1.04-1.55, $\mathrm{p}=0.02$; Lys/ Gln vs. Gln/Gln: $\mathrm{OR}=1.16$, 95\%CI: $1.01-1.34, \mathrm{p}=0.04 ; \mathrm{Gln} /$ Gln vs. Lys/Lys: OR=2.00, 95\%CI: 1.03-3.88, p=0.04; European: $\mathrm{Gln} / \mathrm{Gln}$ vs. Lys/Lys: OR=1.44, 95\%CI: $1.12-1.85$, $\mathrm{p}<$ 0.01; Recessive model: $\mathrm{OR}=1.29$, 95\%CI: 1.03-1.62, $\mathrm{p}=$ 0.03 ). Furthermore, we conducted a subgroup analysis of the control sources and found a significantly increased risk in both the population-based controls (PB) and hospital-based controls (HB) groups (For PB, Lys/Gln vs. Lys/Lys: OR=
1.32, 95\%CI: 1.11-1.58, $\mathrm{p}=0.002$; Dominant model: $\mathrm{OR}=$ 1.52, 95\%CI: 1.13-2.04, p=0.006; For HB, Gln/Gln vs. Lys/ Lys: $\mathrm{OR}=1.53,95 \% \mathrm{CI}$ : 1.08-2.16, $\mathrm{p}=0.02$; Recessive model: $\mathrm{OR}=1.43$, 95\%CI: $1.09-1.89, \mathrm{p}=0.01$ ). However, the subgroup analysis based on smoking and drinking habits showed no significant associations between the XPD Lys751 Gln polymorphism and the risk of EC in any of the four genotype models.

\section{Sensitivity analysis}

There was significant heterogeneity in both the overall and stratified studies. Therefore, the random effects model was employed in the OR calculations. In order to examine the source of heterogeneity, we conducted further subgroup analyses according to the type of cancer, ethnicity, control source and smoking and drinking habits. In the subgroup analysis of the cancer type, significant heterogeneity was found in two studies $(21,34)(\mathrm{Gln} / \mathrm{Gln}$ vs. Lys/Lys: ESCC, $I^{2}=74-29 \%$; EADC, $I^{2}=95-45 \%$; Recessive model: ESCC, $I^{2}=$ 76-29\%; EADC, $I^{2}=96-0 \%$ ). Excluding these two studies resulted in a reduced $I^{2}$ of $29 \%, 45 \%, 29 \%$ and $0 \%$, respectively. Therefore, these two studies were deleted from the subgroup analysis. We then excluded all studies individually in order to test the sensitivity. However, the heterogeneity did not change significantly, indicating that our results were statistically stable and credible. Furthermore, the shape of the funnel plots did not show any signs of asymmetry, 
A

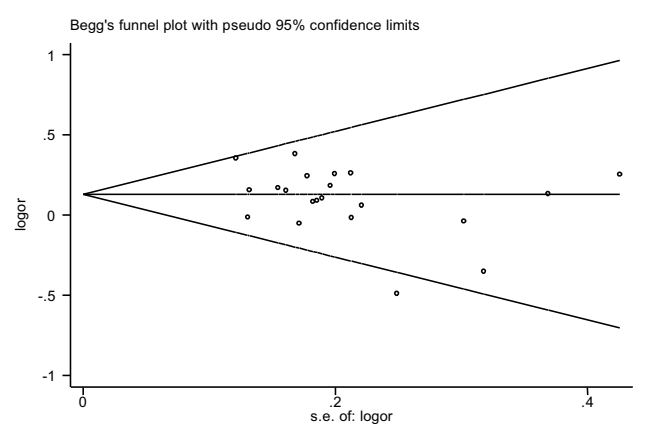

C

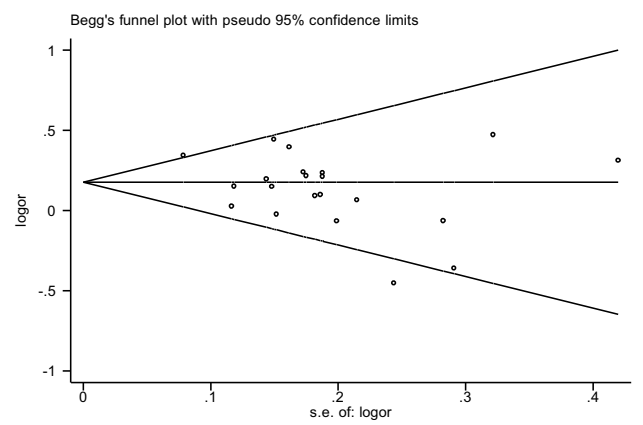

B

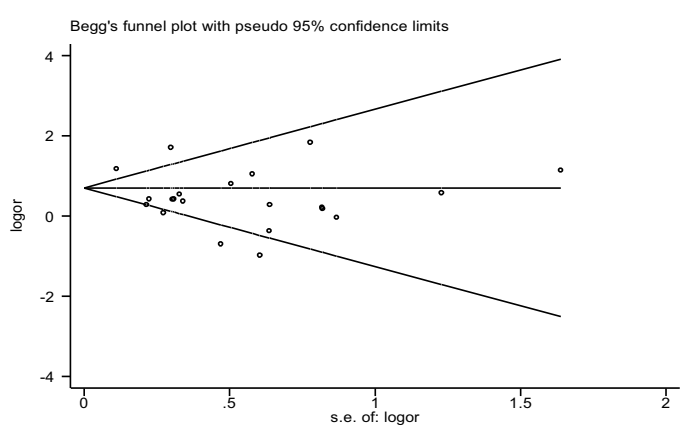

D

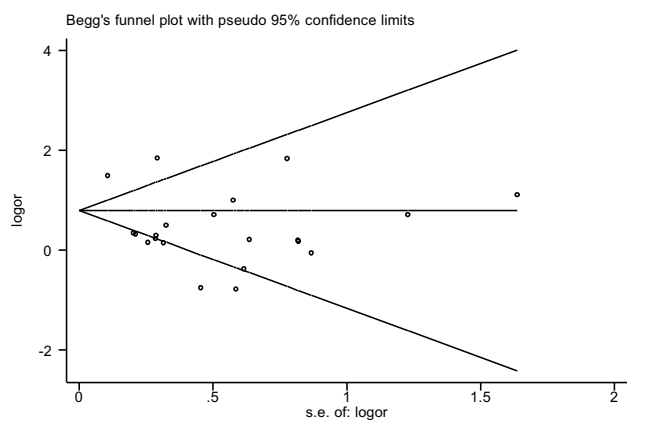

Figure 7. Funnel plot for overall meta-analysis of XPD Lys751GIn polymorphism and esophageal cancer risk (A: Lys/GIn vs. Lys/Lys, B: GIn/Gln vs. Lys/Lys, C: dominant model, D: recessive model)

which suggests that there was no evidence of publication bias among the studies (Fig. 7).

\section{Discussion}

It is well known that DNA repair is a crucial mechanism protecting against gene mutations and carcinogenesis. XPD (also named ERCC) is located at chromosome 19q13.2q13.3 and encodes an ATP-dependent DNA helicase (37). Accumulating evidence indicates racial differences in this gene in the overall population. For example, a study by Horner et al. showed that $64 \%$ of EADC patients are white, while $82 \%$ of ESCC patients are black $(38,39)$. Meanwhile in China, 95\% of patients have ESCC (40). It has also been demonstrated that patients carrying the Gln allele are more prone to developing EC. Furthermore, previous studies have shown that the XPD Lys751Gln polymorphism plays an important role in the development of EC. However, the opposite results have also been reported in some studies. In this meta-analysis, we aimed to confirm the precise association between the XPD Lys751Gln polymorphism and the risk of EC.

This study is the largest meta-analysis of XPD Lys751Gln polymorphisms in EC patients conducted to date. Our results showed a significant association with EC in the overall population. However, we also documented between-study heterogeneity and thus further performed subgroup analyses. Consequently, a significant association was found for both ESCC and EADC. In addition, in the subgroup analysis of ethnicity, all four gene models showed a statistically signifi- cant association between the XPD Lys751Gln polymorphism and the EC risk in Asians, while two models showed this result for European populations (Gln/Gln vs. Lys/Lys: OR= 1.44, 95\%CI: 1.12-1.85, $\mathrm{p}<0.01$; Recessive model: OR= $1.29,95 \%$ CI: $1.03-1.62, \mathrm{p}=0.03$ ), but not mixed populations. The most likely reason for this discrepancy is the presence of differences in genotype distribution among Asian, European and mixed populations. The present findings differ from those of the analysis performed by Ding and Yuan $(41,42)$, perhaps due to the assessment of a higher number of cases and controls in this meta-analysis. However, in the subgroup analysis of the control source, a borderline significantly increased risk was noted in both hospital-based and population-based studies. Therefore, bias may have caused the heterogeneity and/or various outside factors may have increased the risk of EC in our analysis. $\mathrm{Yu}$ et al. reported that the risk of ESCC among smokers with the XPD $751 \mathrm{Gln} /$ Gln genotype is increased eight-fold compared to that observed in wild-type homozygotes (29). In addition, Chen and Sobti et al. found that alcohol intake increases the risk of EC $(24,26)$, although studies by Zhou, $\mathrm{Wu}$ and Xing et al. did not find the same results $(21,25,30)$.

Although a lot of effort and energy have been expended to confirm the association between the XPD 751 polymorphism and the EC risk, the limitations of published studies should not be ignored. First, the number of cases and controls in each study was small and not uniform. Second, the source of controls was not a uniform population in each study, which may have induced non-differential misclassifi- 
cation bias. Third, although we included the factors of smoking and drinking in this meta-analysis, the genotype in various studies $(24,30)$ lack detailed classification, which may indicate bias. Fourth, all EADC patients were from European populations in this meta-analysis, whereas the ESCC patients included both Asians and Europeans. Furthermore, we did not analyze the differences between Asians and Europeans among the ESCC patients in the analysis stratified according to ethnicity, which may have introduced bias into the subgroup analysis results for ESCC. Finally, significant heterogeneity was found in some models, which indicate a failure to confirm marginal associations. In spite of these limitations, our meta-analysis has various advantages. First, nine additional case-control studies were included, which significantly increased the statistical power of the analysis. Second, the quality of the case-control studies included in the current meta-analysis was satisfactory and met the inclusion criteria. Third, the forest map did not show significant publication bias.

In conclusion, the results of this meta-analysis indicate that the XPD Lys751Gln polymorphism increases susceptibility to esophageal cancer in Asian and European, but not mixed, populations. Therefore, the XPD Lys751Gln polymorphism may contribute to the risk of esophageal cancer, including ESCC and EADC. Well-designed studies with large samples are needed for further research.

\section{The authors state that they have no Conflict of Interest (COI).}

\section{Acknowledgement}

We are very grateful to Mr. Hong Xia at the Key Laboratory of Hubei Province for Digestive System Disease for his assistance with the data collection.

$\mathrm{Xu}-$ Feng Guo and Jun Wang contributed equally to this work.

\section{References}

1. Parkin DM, Bray F, Ferlay J, et al. Global cancer statistics 2002. CA Cancer J Clin 55: 74-108, 2005.

2. Jemal A, Siegel R, Ward E, et al. Cancer statistics, 2008. CA Cancer J Clin 58: 71-96, 2008.

3. Lagergren J, Bergström R, Lindgren A, et al. Symptomatic gastroesophageal reflux as a risk factor for esophageal adenocarcinoma. N Engl J Med 340: 825-831, 1999.

4. Lagergren J, Bergström R, Lindgren A, et al. The role of tobacco, snuff and alcohol use in the aetiology of cancer of the oesophagus and gastric cardia. Int J Cancer 85: 340-346, 2000.

5. Lindblad M, Rodríguez LA, Lagergren J, et al. Body mass, tobacco and alcohol and risk of esophageal, gastric cardia, and gastric non-cardia adenocarcinoma among men and women in a nested case-control study. Cancer Causes Control 16: 285-294, 2005.

6. Kubo A, Corley DA. Body mass index and adenocarcinomas of the esophagus or gastric cardia: a systematic review and metaanalysis. Cancer Epidemiol Biomarkers Prev 15: 872-878, 2006.

7. Freedman ND, Abnet CC, Leitzmann MF, et al. A prospective study of tobacco, alcohol, and the risk of esophageal and gastric cancer subtypes. Am J Epidemiol 165: 1424-1433, 2007.

8. Hoeijmakers JH. Genome maintenance mechanisms for preventing cancer. Nature 411: 366-374, 2001.

9. Ishikawa T, Zhang SS, Qin X, et al. DNA repair and cancer: lessons from mutant mouse models. Cancer Sci 95: 112-117, 2004.

10. Yoon $\mathrm{HH}$, Catalano PJ, Murphy KM, et al. Genetic variation in DNA-repair pathways and response to radiochemotherapy in esophageal adenocarcinoma: a retrospective cohort study of the Eastern Cooperative Oncology Group. BMC Cancer 11: 176, 2011.

11. Ouyang FD, Yang FL, Chen HC, et al. Polymorphisms of DNA repair genes XPD, XRCC1, and OGG1, and lung adenocarcinoma susceptibility in Chinese population. Tumour Biol 34: 2843-2848, 2013.

12. Mittal RD, Mandal RK. Genetic variation in nucleotide excision repair pathway genes influence prostate and bladder cancer susceptibility in North Indian population. Indin J Hum Genet 18: 4755, 2012.

13. Engin AB, Karahalil B, Engin A, et al. DNA repair enzyme polymorphisms and oxidative stress in a Turkish population with gastriccarcinoma. Mol Biol Rep 8: 5379-5386, 2011.

14. Huang MY, Wang JY, Huang ML, et al. Polymorphisms in XPD and ERCC1 Associated with Colorectal Cancer Outcome. Int J Mol Sci 14: 4121-4134, 2013.

15. Lau J, Ioannidis JP, Schmid CH. Quantitative synthesis in systematic reviews. Ann Intern Med 127: 820-826, 1997.

16. DerSimonian R, Laird N. Meta-analysis in clinical trials. Control Clin Trials 7: 177-188, 1986.

17. Mantel N, Haenszel W. Statistical aspects of the analysis of data from retrospective studies of disease. J Natl Cancer Inst 22: 719$748,1959$.

18. Huang CG, Liu T, Lv GD, et al. Analysis of XPD genetic polymorphisms of esophageal squamous cell carcinoma in a population of Yili Prefecture, in Xinjiang, China. Mol Bil Rep 39: 709714, 2012.

19. Wang LZ. Association of tagging SNPs in ERCC2 gene with esophageal squamous cell carcinoma in Henan Han population. Department of Epidemiology and Bioststistics College of Public Health. 2012: 17-18.

20. Li RZ, Sun J. Association between XPD gene polymorphisms and esophageal quamous cell carcinoma. Mol Med Rep 7: 674-678, 2013.

21. Wu XB. XPD Gene polymorphisms and susceptibility to develping esophageal cancer. A thesis submitted to Zhengzhou University for the degree of Master. 2010: 30-34.

22. Zhai XD, Mo YN, Xue XQ, et al. XRCC1 codon 280 and ERCC2 codon 751 polymorphisms and risk of esophageal squamous cell carcinoma in a Chinese population. Bull Cancer 96: E61-E65, 2009.

23. Pan J, Lin J, Izzo JG, et al. Genetic susceptibility to esophageal cancer: the role of the nucleotide excision repair pathway. Carcinogenesis 30: 785-792, 2009.

24. Chen MR, Chen JM, Guo P, et al. Polymorphism of DNA repair gene XPD and XRCC land its relationship with esophageal squamous cell carcinoma. Fudan University J Med Sci 35: 273281, 2008.

25. Zhou MR. Correlation of nucleotide excision repair gene XPC and XPD polymorphisms to esophageal squamous cell carcinoma and gastric cardiac adenocarcinoma. Hebei University for the degree of Master. 2007: 43-44.

26. Sobti RC, Singh J, Kaur P, et al. XRCC1 codon 399 and ERCC2 codon 751 polymorphism, smoking, and drinking and risk of esophageal squa mous cell carcinoma in a North Indian population. Cancer Genet Cytogenet 175: 91-97, 2007.

27. Zhang WC, Yin LH, Pu YP, et al. Relaionship between polymorphisms of DNA repair genes and esophageal cancer susceptibility. Chin J Public Health 22: 557-558, 2006.

28. Ye W, Kumar R, Bacova G, et al. The XPD 751Gln allele is asso- 
ciated with an increased risk for esophageal adenocarcinoma: a population-based case-control study in Sweden. Carcinogenesis 27: 1835-1841, 2006.

29. Yu HP, Wang XL, Sun X, et al. Polymorphisms in the DNA repair gene XPD and susceptibility to esophageal squamous cell carcinoma. Cancer Genet Cytogenet 154: 10-15, 2004.

30. Xing D, Qi J, Tan W, et al. Association of genetic polymorphisms in the DNA repair gene XPD with risk of lung and esophageal cancer in a Chinese population in Beijing. Chinese Journal of Medical Genetics 20: 35-38, 2003 (in Chinese, Abstract in English).

31. Xing D, Tan W, Wei Q, et al. Polymorphisms of the DNA repair gene XPD and risk of lung cancer in a Chinese population. Lung Cancer 38: 123-129, 2002.

32. Ferguson HR, Wild CP, Anderson LA, et al. No association between hOGG1, XRCC1, and XPD polymorphisms and risk of reflux esophagitis, Barrett's esophagus, or esophageal adenocarcinoma: results from the factors influencing the Barrett's adenocarcinoma relationship case-control study. Cancer Epidemiol Biomarkers Prev 17: 736-739, 2008.

33. Tse D, Zhai R, Zhou W, et al. Polymorphisms of the NER pathway genes, ERCC1 and XPD are associated with esophageal adenocarcinoma risk. Cancer Causes Control 19: 1077-1083, 2008.

34. Doecke J, Zhao ZZ, Pandeya N, et al. Polymorphisms in MGMT and DNA repair genes and the risk of esophageal adenocarcinoma. Int J Cancer 123: 174-180, 2008.
35. Liu G, Zhou W, Yeap BY, et al. XRCC1 and XPD polymorphisms and esophageal adenocarcinoma risk. Carcinogenesis 28: 12541258, 2007.

36. Casson AG, Zheng Z, Evans SC, et al. Polymorphisms in DNA repair genes in the molecular pathogenesis of esophageal (Barrett) adeno carcinoma. Carcinogenesis 26: 1536-1541, 2005.

37. Lunn RM, Helzlsouer KJ, Parshad R, et al. XPD polymorphisms: effects on DNA repair proficiency. Carcinogenesis 21: 551-555, 2000.

38. Horner M, Ries L, Krapcho M, et al. SEER Cancer Statistics Review, 1975-2006, National Cancer Institute. Bethesda, MD. [cited 2013 Nov 20]. Available online: http://seer.cancer.gov/csr/1975_20 06/, based on November 2008 SEER data submission, posted to the SEER web site, 2009.

39. Berry MF. Esophageal cancer: staging system and guidelines for staging and treatment. J Thorac Dis 6: S289-S297, 2014.

40. Mao YS, He J, Xue Q, et al. Nationwide speaking tour of standardized diagnosis and treatment for esophageal cancer. Clin $\mathbf{J}$ Gastrointest Surg 19: 801-804, 2013.

41. Ding DP, Ma WL, He XF, et al. XPD Lys751Gln polymorphism and esophageal cancer susceptibility: a meta-analysis of casecontrol studies. Mol Biol Rep 39: 2533-2540, 2012.

42. Yuan L, Cui D, Zhao EJ, et al. XPD Lys751Gln polymorphism and esophageal cancer risk: A meta-analysis involving 2288 cases and 4096 controls. World J Gastroenterol 17: 2343-2348, 2011.

(C) 2015 The Japanese Society of Internal Medicine http://www.naika.or.jp/imonline/index.html 